\title{
The Impact of Social Media on the Acceptance of the COVID-I9 Vaccine: A Cross-Sectional Study from Saudi Arabia
}

\author{
Adel Alfatease' \\ Ali M Alqahtani (iD ${ }^{2}$ \\ Khalid Orayj iD ${ }^{3}$ \\ Sultan M Alshahrani (iD ${ }^{3}$ \\ 'Pharmaceutics Department, College of \\ Pharmacy, King Khalid University, Abha, \\ Saudi Arabia; ${ }^{2}$ Pharmacology \\ Department, College of Pharmacy, King \\ Khalid University, Abha, Saudi Arabia; \\ ${ }^{3}$ Clinical Pharmacy Department, College \\ of Pharmacy, King Khalid University, \\ Abha, Saudi Arabia
}

Introduction: Social media platforms are used by many people to seek and share healthrelated information that may influence their decision-making about COVID-19 vaccination. Purpose: The objective of this study is to understand the influence of social media on the attitudes and willingness of the general public of the Aseer region of Saudi Arabia to receive COVID-19 vaccination.

Materials and Methods: A cross-sectional self-administrated online survey was conducted in Saudi Arabia Aseer region, where 613 persons willingly took part in the survey in April and May 2021. Residents of Aseer in Saudi Arabia, who are over the age of 18 (eligible for COVID-19 vaccination) and willing to participate in the survey, were included in the study. Results: Overall, 74.6\% agreed that the COVID-19 vaccine was misrepresented via social media. However, $37 \%$ of those respondents strongly agreed that social media had increased their willingness to get the COVID-19 vaccine. In addition, employees reported $(21.8 \%)$ or strongly agreed $(28 \%)$ that the quantity and quality of information on social media has a detrimental impact on their psychological well-being. Additionally, participants also agreed $(21.8 \%)$ or strongly agreed $(28 \%)$ that social media had a negative effect on their psychological condition.

Conclusion: The study provides that there was a high degree of awareness indicated among Aseer population regarding misleading information about COVID-19 vaccination via social media. Thus, social media that can share up-to-date scientific information about vaccination must be utilized optimally by the government to assist people in making decisions about accepting vaccinations.

Keywords: social media, COVID-19, vaccination, survey, Saudi Arabia

\section{Introduction}

The Coronavirus (COVID-19) that results from the severe acute respiratory syndrome coronavirus 2 (SARS-CoV-2) is a major international public health concern, with 179 million active cases and 3 million death recorded. ${ }^{1,2}$ The Centers for Disease Control and Prevention (CDC) in the United States raised concerns that a variant of SARS-CoV-2 known as B.1.1.7, which was initially discovered in England in late 2020, was found in ten US states. At the same time, there are several other variants identified, namely, B.1.351 and B.1.1.28. ${ }^{1,3}$ Presently, there is another variant found in India, which is named the delta variant (B.1.617.2). ${ }^{4}$ The spreading of the variants has become a major public health problem because of the potential impact on case rates, hospital capacities, and ultimately death. ${ }^{3}$ There has
Correspondence: Sultan M Alshahrani Clinical Pharmacy Department, College of Pharmacy, King Khalid University, Abha, 6I44I, Saudi Arabia

Tel +966508747473

Email shahrani@kku.edu.sa 
been a remarkable extent to which the pandemic has worsened current economic and health inequalities. However, the remarkable speed of developing several COVID-19 vaccines (AstraZeneca, Sinopharm, Sinovac, Pfizer, and Moderna vaccines) and their immediate authorization for emergency use in less than one year is a great achievement for the scientific community. ${ }^{5,6}$ Despite the overall favorable safety and effectiveness profiles of vaccines, the processes which have facilitated the rapid development have been a public concern with potential adverse impacts on vaccination acceptance that have led to the vaccine hesitancy. ${ }^{7}$ Although vaccine hesitation has a long history, it is reasonable to claim that today the Internet provides misinformation. Fear and misunderstandings of vaccine development and approvals likely make the spreading of misinformation easier. ${ }^{8,9}$

Social media are also used efficiently to notify the general population about the consequences of the pandemic. In addition, emerging infectious diseases like COVID-19 lead to enhanced public use and desire for all types of information from media. Social media thus has an important impact on perception of disease outbreaks, decision-making, and risk behavior. ${ }^{10-12}$ As people share information on social media, such information can be accurate or inaccurate. Accurate and timely reporting on emerging risks such as SARS-CoV-2 is therefore essential to the public. $^{13,14}$ In reaction to a global public health crisis, social media users generally develop and share information on healthcare available from local and international sources. Meanwhile, professionals and governments in the health sector have adopted social media to control and manage negative health crises. ${ }^{15-17}$ However, various age groups prefer various social media sites, whereas the present study utilized Twitter, WhatsApp, and Facebook for data collection regarding the impact of social media on the vaccine. The World Health Organization (WHO) has declared that most of the social media platforms are sources of misinformation regarding the COVID-19 which may lead to significant risk to the public health. ${ }^{18}$ In Saudi Arabia, the Ministry of Health has launched a vaccine campaign using a mobile application entitled Sehaty, which makes it easier to register for COVID-19 vaccination. Several vaccination centers have also been built in various cities throughout the country. The PfizerBioNTech COVID-19 Vaccine campaign started on 17 December 2020 to supply all residents of Saudi Arabia with free vaccines. ${ }^{19}$ This study aims to understand the influence of social media on the attitudes and willingness of the general public of the Aseer region of Saudi Arabia to receive vaccination against COVID-19.

\section{Materials and Methods Study Design and Measure}

Following some earlier studies, ${ }^{20-23}$ a self-administered, structured and closed questionnaire was established and afterward adapted to suit the common audience of the Saudi Arabia Aseer region. Then a pilot test was performed to ensure the validity of the survey and assess the language of the study carried out by a linguistic expert. The questionnaire was written in English and also translated into Arabic by a professional. It was made available to participants through several social media platforms (Twitter, WhatsApp, and Facebook). The data was collected in April and May 2021. Residents of Saudi Arabia who are over the age of 18 (eligible for COVID-19 Vaccination) and willing to participate in the survey were included in the study. The study excluded people who were not willing to give their consent. Data collection consisted of the following steps: Participants' demographic characteristics and perspectives on the impact of social media on acceptance of the COVID-19 vaccine were collected, and their opinions on the effectiveness of the vaccination. A Google Form questionnaire was created for this study. A total of 613 persons willingly took part in the survey. The average amount of time required to complete the form was 5 minutes. A self-administered questionnaire was created, and the pilot sample was then tested for validation to ensure its quality and internal reliability. The Cronbach Alpha factor (calculated for 14 questions) was determined as 0.782 . In addition, three experts working within this field provided advice regarding this process. The pilot study results were not included in the final analysis.

\section{Statistical Analysis}

The questionnaires were reviewed, and the data were cleaned, coded, and inputted in the SPSS version 20 (IBM Corp., Armonk, NY, USA). The results were obtained through the application of both descriptive and inferential statistics. The questions in the questionnaire, if answered yes, were classified as either positive or negative impact of social media toward COVID-19 vaccines. For the positive attitude question, strongly agree and agree will be considered as positive attitude, while neutral, disagree, and strongly disagree will be negative attitude (control). 
Then, logistic regression was applied to identify independent factors associated with positive attitudes toward social media. The dependent factors are the questions with positive attitude toward social media, while independent factors included, sex, age, university level, and monthly income, employment status, and residence area. They were considered as a priori factors and were incorporated in the logistic regression model. Odds ratios (ORs) and $95 \%$ confidence intervals (CIs) were used to detect correlations between dependent and independent variables. $P$ value $<0.05$ was considered significant.

\section{Ethical Considerations}

The data collection processes were standardized, and no personal information about the participants was collected or stored. The remaining information was kept confidential during the study as well as during data analysis. The participants were asked for their consent before the beginning of the survey. They were not asked about their ID nor any personal information. Participation in the study was completely voluntarily.

The World Medical Association [WMA] Declaration of Helsinki: Ethical standards for medical research involving human people, as amended by the 59th WMA (ECM\#2021-5415), Seoul, Korea, was followed in this study. Aside from that, no personally identifiable information about the patients was collected. In addition, the Research Ethics Committee at King Khalid University (HAPO-06-B-001) has reviewed and agreed on this project: Approval No. ECM\#2021-5415; Approval date 0205-2020.

\section{Results}

\section{Demographic Characteristics}

The study questionnaire was completed by 613 participants who fulfilled the inclusion criteria, with ages ranging from 18 to $>55$ years old. Most of the participant were young adults (18-25 years; $35.9 \%$ ) followed by $26-35$ years $(30.7 \%), 36-45$ years $(22.8 \%), 46-55$ years $(8.6 \%)$ and $>55$ years $(2 \%)$. Here, 370 participants $(60.4 \%)$ were females, while 243 participants (39.6\%) were males. Considering the level of education, $414(67.5 \%)$ individuals graduated from university, followed by $17.8 \%$ for high school or lower and $14.7 \%$ for a postgraduate degree. The monthly income was less than 5000 SR for 241 (39.3\%) participants, while 164 (26.8\%) reported having 8000-15,000 SR monthly income (Table 1). Apart from
Table I Demographic Presentation of the Respondents

\begin{tabular}{|c|c|}
\hline Demographic & n (\%) $N=613$ \\
\hline Sex (male) & $243(39.6)$ \\
\hline \multicolumn{2}{|l|}{ Age group } \\
\hline $18-25$ years & $220(35.9)$ \\
\hline $26-35$ years & $188(30.7)$ \\
\hline $36-45$ years & $140(22.8)$ \\
\hline $46-55$ years & $53(8.6)$ \\
\hline More than 55 years & $12(2)$ \\
\hline \multicolumn{2}{|l|}{ Level of Education } \\
\hline High school or lower & $109(17.8)$ \\
\hline University level & $414(67.5)$ \\
\hline Postgraduate degree & $90(14.7)$ \\
\hline \multicolumn{2}{|l|}{ Employment status } \\
\hline Unemployed & $147(24)$ \\
\hline Student & $188(30.7)$ \\
\hline Government job & $226(36.9)$ \\
\hline Private job & $52(8.5)$ \\
\hline \multicolumn{2}{|l|}{ Monthly income } \\
\hline Less than 5000 Saudi Riyal (SR) & $24 \mid(39.3)$ \\
\hline $5000-8000$ SR & $99(16.2)$ \\
\hline $8000-15,000$ SR & $164(26.8)$ \\
\hline More than 15,000 SR & $109(17.8)$ \\
\hline \multicolumn{2}{|l|}{ Residence area } \\
\hline Rural & $109(17.8)$ \\
\hline Urban & $504(82.2)$ \\
\hline $\begin{array}{l}\text { Have you been infected or in contact with a person } \\
\text { infected with the emerging coronavirus during the } \\
\text { past six months? (yes) }\end{array}$ & $98(16)$ \\
\hline
\end{tabular}

that, the vast majority of those who took part were residents of urban areas (82.2\%). However, $16 \%$ of participants reported being infected or contacted by an infected person during the past six months with the emerging COVID-19.

Table 2 presents the perspectives of the participants on the social media impact of getting the COVID-19 vaccine. Over half $(74.6 \%)$ of participants agreed or strongly agreed that there was misinformation in the social media about the COVID-19 vaccination. Also, a similar percentage $(72.8 \%)$ are agreed or strongly agreed that they would obtain the information directly from the competent authorities without referring to social media. However, $37 \%$ of participants strongly agreed that social media had increased the willingness to take the COVID-19 vaccine. 
Table 2 The Perspectives of the Participants on the Social Media Impact of Getting the COVID-19 Vaccine

\begin{tabular}{|c|c|c|c|c|c|}
\hline \multirow[t]{2}{*}{ Question } & $\mathbf{N}(\%)$ & $\mathbf{N}(\%)$ & $\mathbf{N}(\%)$ & $\mathbf{N}(\%)$ & $\mathbf{N}(\%)$ \\
\hline & $\begin{array}{l}\text { Strongly } \\
\text { Disagree }\end{array}$ & Disagree & Neutral & Agree & $\begin{array}{c}\text { Strongly } \\
\text { Agree }\end{array}$ \\
\hline $\begin{array}{l}\text { Social media carries wrong information regarding the COVID-19 vaccine, and } \\
\text { it should not be taken without consulting specialists }\end{array}$ & $13(2.1)$ & $32(5.2)$ & $110(17.9)$ & I7| (27.8) & $287(46.8)$ \\
\hline $\begin{array}{l}\text { I make sure to follow medical professionals through social media to know the } \\
\text { latest developments about the vaccine }\end{array}$ & $19(3)$ & $33(5.3)$ & $114(18.5)$ & $178(29)$ & $269(43.8)$ \\
\hline $\begin{array}{l}\text { I prefer to obtain the information directly from the competent authorities } \\
\text { without referring to social media }\end{array}$ & $12(1.9)$ & $35(5.7)$ & $106(17.2)$ & $145(23.6)$ & $315(51.3)$ \\
\hline I follow with interest the number of vaccine recipients through social media & $48(7.8)$ & $70(11.4)$ & $143(23.3)$ & $169(27.5)$ & $183(29.8)$ \\
\hline Social media has increased my eagerness to take the COVID-19 vaccine & $38(6.1)$ & $50(8.1)$ & $130(2 \mid .2)$ & $168(27.4)$ & $227(37)$ \\
\hline $\begin{array}{l}\text { I share the vaccine information I get from social media with my family and } \\
\text { friends without making sure the information is correct }\end{array}$ & $154(25.1)$ & $128(20.8)$ & $117(19)$ & $101(16.4)$ & $113(18.4)$ \\
\hline $\begin{array}{l}\text { I advise others to follow social media constantly to know the latest } \\
\text { developments about the vaccine in the future }\end{array}$ & $60(9.7)$ & $69(11.2)$ & $185(30.1)$ & $149(24.3)$ & $150(24.4)$ \\
\hline $\begin{array}{l}\text { Follow up with interest on social media on a daily basis regarding the latest } \\
\text { developments in the COVID-19 vaccine }\end{array}$ & $54(8.8)$ & $74(12)$ & $155(25.2)$ & $161(26.2)$ & $169(27.5)$ \\
\hline $\begin{array}{l}\text { The amount and quality of information on social media negatively affects my } \\
\text { psychological state }\end{array}$ & $64(10.4)$ & $86(14)$ & $157(25.6)$ & $134(21.8)$ & $172(28)$ \\
\hline $\begin{array}{l}\text { The means of communication affect the delivery of a meaningful message to } \\
\text { the community about receiving the COVID-19 vaccine }\end{array}$ & $14(2.2)$ & $25(4)$ & $122(19.9)$ & $175(28.5)$ & $277(45.1)$ \\
\hline
\end{tabular}

In contrast, more than half of the participants demonstrated a negative attitude towards sharing vaccine information retrieved from social media. Most participants disagreed, strongly disagreed, or were neutral towards advising others to constantly follow social media to know the vaccine's latest developments. Also, the participants agreed $(21.8 \%)$ or strongly agreed $(28 \%)$ that the amount and quality of information on social media negatively affect their psychological state.

\section{Logistic Regression Model Examining Factors Affecting the Positive Attitude Toward Social Media Regarding COVID-19}

Table 3 shows the questions in the questionnaire, if answered yes, were classified to either positive or negative impact of social media toward COVID-19 vaccines acceptance. Table 4 represents the logistic regression model which revealed a significant association between some independent variables and the positive attitude toward social media. Male participants were less likely to be influenced by social media when deciding to take COVID-19 vaccines ( $\mathrm{p}=0.041$, OR: 0.679, CI: $0.468-$ 0.985). Compared to participants with lower education level, participants with university education level or with postgraduate degree level were less likely to share information obtained from social media on the vaccine without making sure that the information were correct $(\mathrm{p}=0.01$, OR: 0.546 , CI: 0.344 $0.866)$ and ( $p=0.003$, OR: $0.331, \mathrm{CI}: 0.158-0.693)$ respectively. Additionally, participants with postgraduate degree were in general less likely to have a positive attitude toward using of social media as s source of information regarding COVID-19 vaccine, see Tables 3 and 4.

\section{Discussion}

Historically, vaccinations have led to the elimination of smallpox and significant decreases in rubella, mumps, polio, chickenpox, and various other infectious diseases. The COVID-19 pandemic resulted in over 100 million cases and more than 2 million deaths globally as of January 2021, and vaccination is likely to be vital in having pandemic prevention and management. Generally, the study of vaccinations illustrates the long 
Table 3 The Questions That Measure the Attitude Toward Social Media (SM)

\begin{tabular}{|l|c|}
\hline \multicolumn{2}{|l|}{ Questions } \\
\hline $\begin{array}{l}\text { Social media carries wrong information regarding the COVID-I9 vaccine, and it should not be taken without } \\
\text { consulting specialists }\end{array}$ & Negative attitude to SM \\
\hline I make sure to follow medical professionals through social media to know the latest developments about the vaccine & Positive attitude to SM \\
\hline I prefer to obtain the information directly from the competent authorities without referring to social media & Negative attitude to SM \\
\hline I follow with interest the number of vaccine recipients through social media & Positive attitude to SM \\
\hline Social media has increased my eagerness to take the COVID-I9 vaccine & Positive attitude to SM \\
\hline I share the vaccine information I got from social media with my family and friends without making sure the information & Positive attitude to SM \\
\hline is correct & Positive attitude to SM \\
\hline I advise others to follow social media constantly to know the latest developments about the vaccine in the future & Positive attitude to SM \\
\hline The amount and quality of information on social media negatively affects my psychological state & Negative attitude to SM \\
\hline
\end{tabular}

gaps between scientific design, development, production, approval, and population-based use. The COVID-19 pandemic has sparked a surge in global vaccine research and development (R\&D). ${ }^{5,6,24-30}$ Several vaccines are available, including the AstraZeneca (Oxford), Sinopharm, Sinovac, Pfizer (BioNTech), and Moderna vaccines. ${ }^{6}$ Social media has become a stage for public opinion, perception, and attitudinal opinion on different events or policies relating to public health concerning COVID-19 due to the pandemic. Social media has become a helpful element for communicating critical information to governments, agencies, and academics. Several projects use social media information to track infectious disease outbreaks and assess public opinion attitudes, behavior, and perceptions. ${ }^{31-35}$ The rapid and dynamic social media environment was used in this study to acquire Saudi Arabian perspectives into the COVID-19 vaccination, while the previous outlined was followed. ${ }^{20-23}$

Social media was among the most common ways to learn about news and updates on infectious diseases in developing countries. During the COVID-19 pandemic, social media played a vital role in sharing reliable or misleading statements. In addition to the COVID-19 pandemic, there have been widespread misleading statements or information that presents a severe public health problem, which leads to modifying the patterns of infection and the extent and depth of the pandemic. To the best of our knowledge, this study is the first of a kind to explore the impact of social media on acceptance of COVID19 vaccination in Saudi Arabia. All media could share this information, but the role played by social media in promoting misinformation should be of particular concern. In addition, scholars discovered misinformation about healthcare on social media sites, including information about vaccines and other virus epidemics. ${ }^{13,36-39}$ In the present study, $46.8 \%$ (strongly agree) and $27.8 \%$ (agree) reported that social media carries wrong information regarding the COVID-19 vaccine, while it needs to be taken after consulting the healthcare professionals. Social media have taken initiatives from the beginning of the pandemic to prevent misinformation on their sites. Facebook has stated that it will remove all postings with false claims regarding coronaviruses and all vaccines. Twitter has added labels on tweets having misinformation about the COVID-19 vaccine and erasing misinformation, while YouTube is devoted to blocking content with false vaccines claimed. ${ }^{40}$ In the current study, those who have an education level up to university $(67.5 \%)$ are more aware of sharing information about the vaccine that they got from social media $(\mathrm{P}=0.01)$. Similar negative attitudes in sharing information on social media is found for postgraduates $(\mathrm{P}=0.003)$. Saudi Arabians have a higher perception of the COVID-19 pandemics (75.7\%) than non-Saudi Arabians (65.9\%), according to the previous studies. ${ }^{41,42}$ The previous study reported that about $83.6 \%$ got their information about COVID-19 pandemics from official sources, while $68.7 \%$ trusted the information shared by the Saudi health ministry. ${ }^{42}$ Presently, $51.3 \%$ strongly agreed to obtain the information directly from competent authorities. Yet, despite the negative impact of the social media towards sharing information of COVID-19, there is a more significant advantage of social media in influencing the vaccination. The transparency and social debates about public health are made possible by social media. Consequently, the ability to exchange 


\begin{tabular}{|c|c|c|c|c|c|c|c|c|c|c|c|c|c|c|c|c|c|c|c|c|c|}
\hline 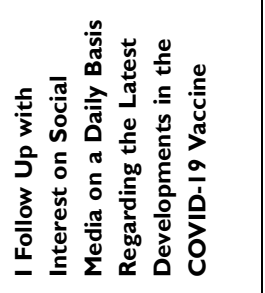 & 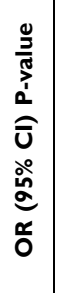 & 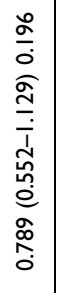 & & $\Phi$ & 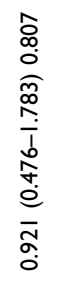 & 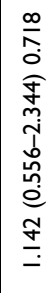 & 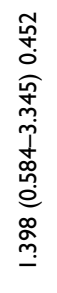 & 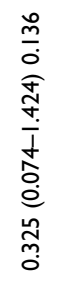 & & $\Phi$ & 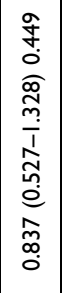 & 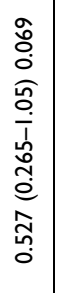 & & $\stackrel{\Phi}{\Phi}$ & 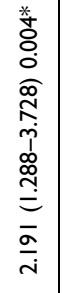 & 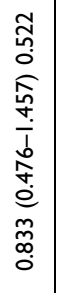 & 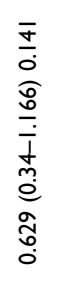 & & $\stackrel{\longleftarrow}{\Phi}$ & 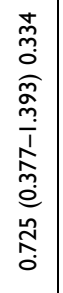 & 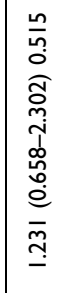 \\
\hline 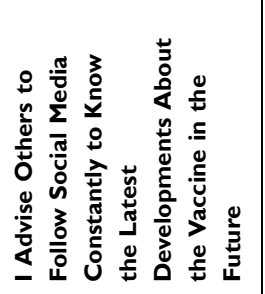 & 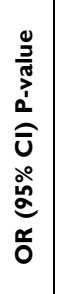 & 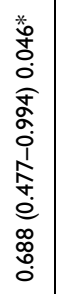 & & $\Phi$ & 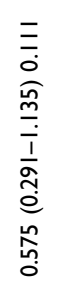 & 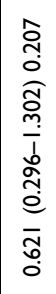 & 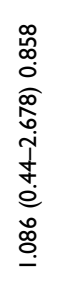 & 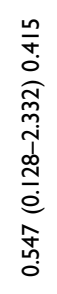 & & $\Phi$ & 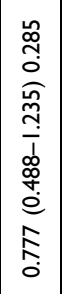 & 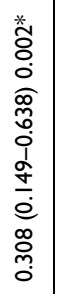 & & $\Phi$ & 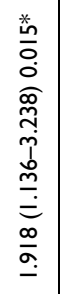 & 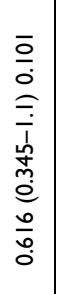 & 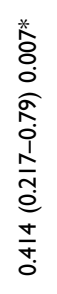 & & $\stackrel{\Phi}{\Phi}$ & 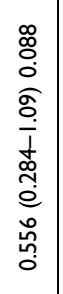 & 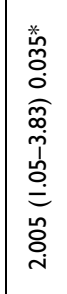 \\
\hline 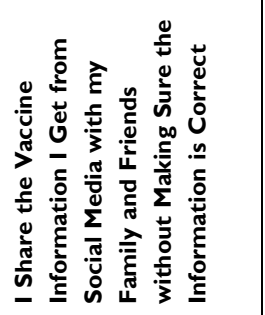 & 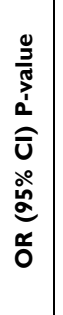 & 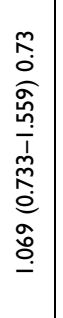 & & $\Phi$ & 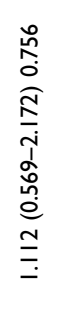 & 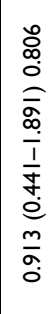 & 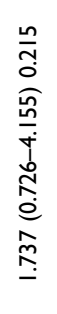 & 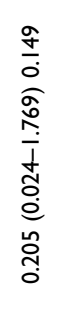 & & $\stackrel{\Phi}{\Phi}$ & 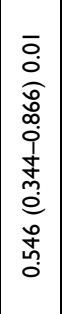 & 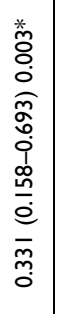 & & $\stackrel{\Phi}{\underline{\Phi}}$ & 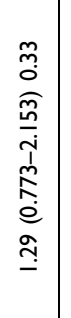 & 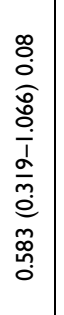 & 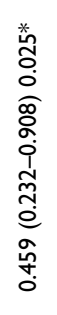 & & $\stackrel{\Phi}{\Xi}$ & 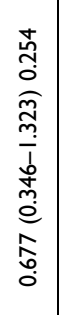 & 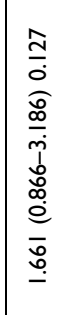 \\
\hline 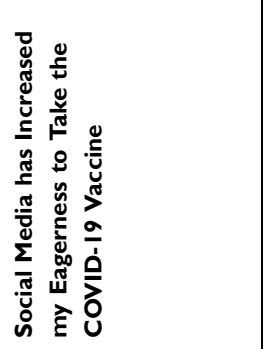 & 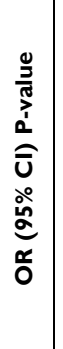 & 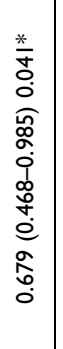 & & $\Phi$ & 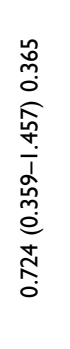 & 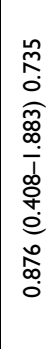 & 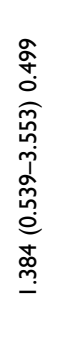 & 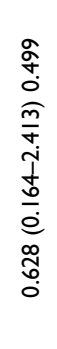 & & $\Phi$ & 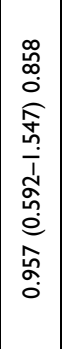 & 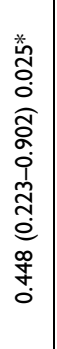 & & 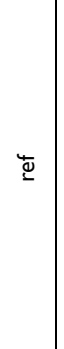 & 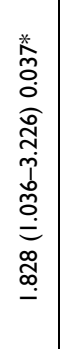 & 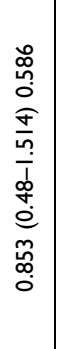 & 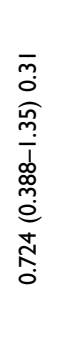 & & $\stackrel{\Xi}{\Phi}$ & 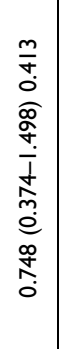 & 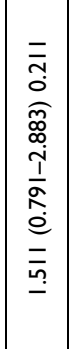 \\
\hline 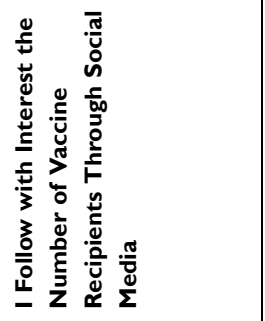 & 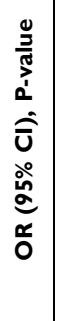 & 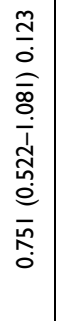 & & $\stackrel{\bar{\Phi}}{\underline{\Phi}}$ & 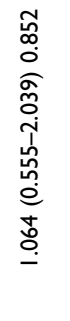 & 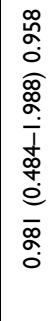 & 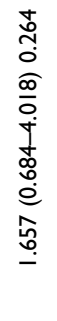 & 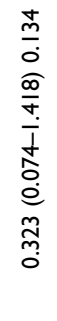 & & $\Phi$ & 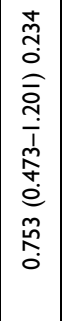 & 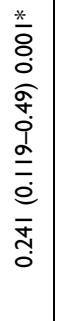 & & $\stackrel{\Phi}{\Phi}$ & 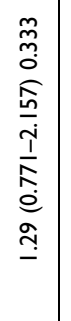 & 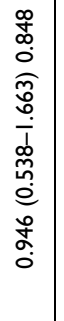 & 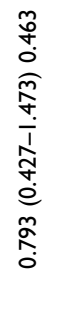 & & $\stackrel{\Xi}{ \pm}$ & 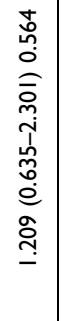 & 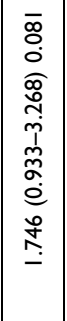 \\
\hline 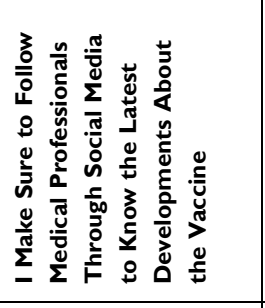 & 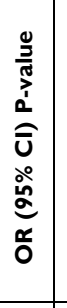 & 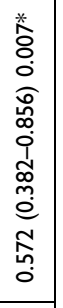 & & $\stackrel{\Phi}{\Phi}$ & 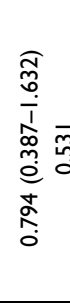 & 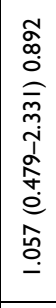 & 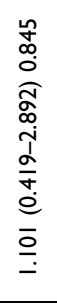 & 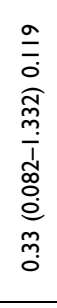 & & $\Phi$ & 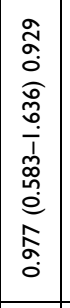 & 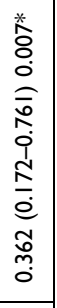 & & 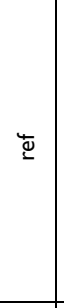 & 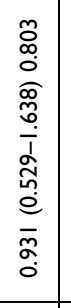 & 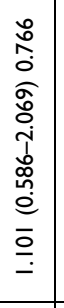 & 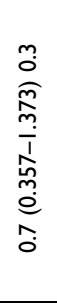 & & 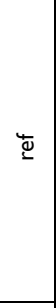 & 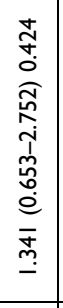 & 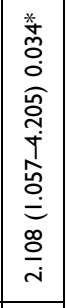 \\
\hline 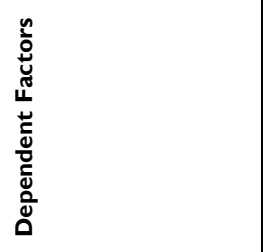 & 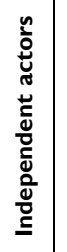 & 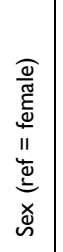 & 总 & $\begin{array}{l}\tilde{N} \\
\underline{\omega}\end{array}$ & 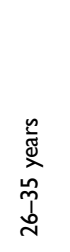 & 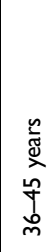 & 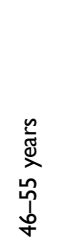 & 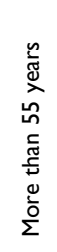 & 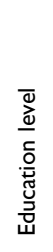 & 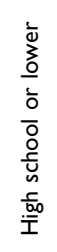 & 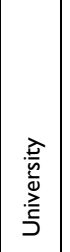 & 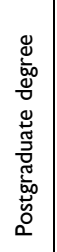 & 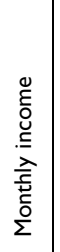 & 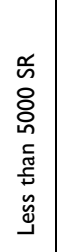 & 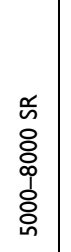 & 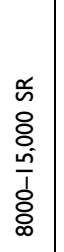 & 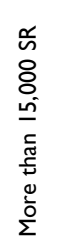 & 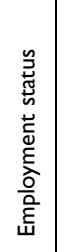 & 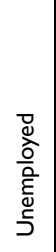 & 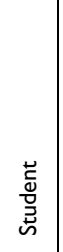 & 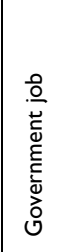 \\
\hline
\end{tabular}




\begin{tabular}{|c|c|c|}
\hline 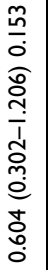 & $\begin{array}{l}\frac{\infty}{T} \\
0 \\
\text { E } \\
\vdots \\
1 \\
0 \\
+ \\
0 \\
0 \\
0 \\
0 \\
0\end{array}$ & 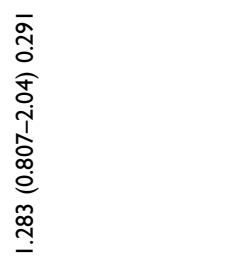 \\
\hline 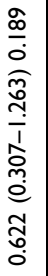 & 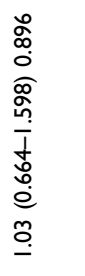 & 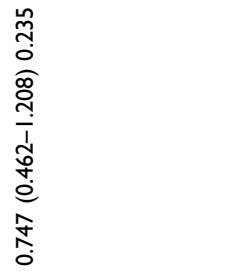 \\
\hline 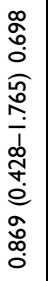 & 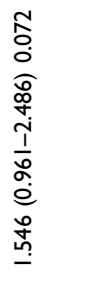 & 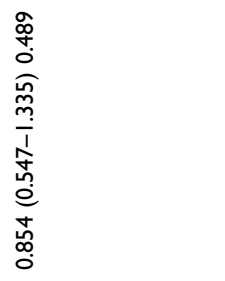 \\
\hline 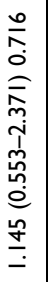 & 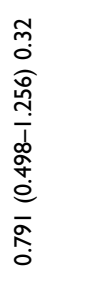 & 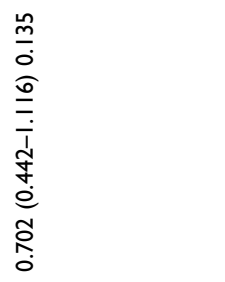 \\
\hline 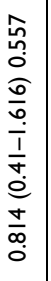 & 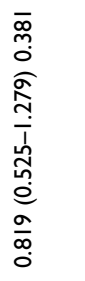 & 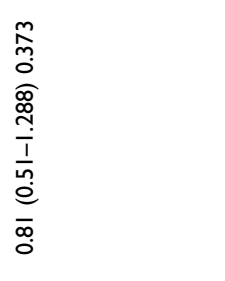 \\
\hline 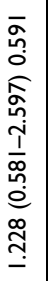 & 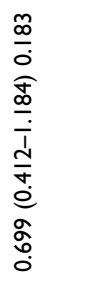 & 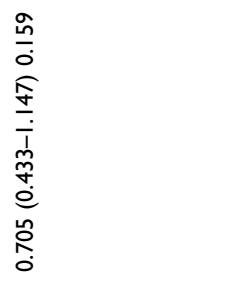 \\
\hline 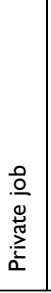 & 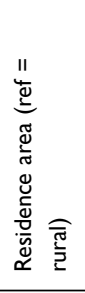 & 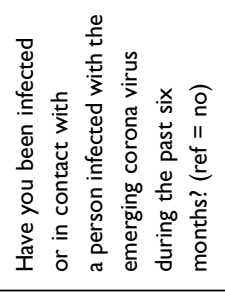 \\
\hline
\end{tabular}

information about the vaccination experiences more than at any other moment in human history makes tracking positive and negative impacts of the vaccine easier for researchers. ${ }^{43}$ This study also found similar observations in participants, whereas more than $50 \%$ have a positive attitude towards getting information about vaccine recipients through social media. Postgraduate $(\mathrm{P}=0.001)$ are significantly aware of this impact. In the present study, more than $50 \%$ have a positive attitude toward taking the COVID-19 vaccine, which is lower than the vaccine hesitancy in the earlier study conducted in Saudi Arabia. ${ }^{19}$ Also, the follow-up with interest on the latest developments regarding the COVID-19 vaccine was found in positive attitudes towards social media. Social media may also be utilized more efficiently to update the public about the health information in the pandemic, while almost half of the participants demonstrated a negative attitude towards social media (30.1\% neutral).

The COVID-19 pandemic led to immediate losses such as the breakdown of the health care system and the global economic situation. Moreover, the long-term alteration of social and economic activity has dramatically affected mental health. As social media has become a key source of information and communication, there is a spread of misinformation about COVID-19 on numerous online social platforms. According to recent studies, spreading misleading information is causing widespread panic among people in several countries. Several studies have demonstrated that social media can spread misinformation, alter people's mentality, and indirectly create psychological traumas as observed by prior incidents. ${ }^{44-49}$ In the present study, almost half of the participants showed a positive attitude and agreed that the amount and quality of information on social media negatively affect their psychological state. While it also stated that the actual meaning of the receiving of the COVID-19 vaccine is affected, whereas $45.1 \%$ of participants are strongly supportive. As a result, social media plays an important influence on people's perceptions of disease exposure, decision-making process, and risk behaviors. ${ }^{11,12}$ There are some limitations to the outcomes of this study, while the major one was the study represents only the Aseer region of Saudi Arabia. It is possible that the use of social media in data collection decreased the diversity of the sample population.

\section{Conclusion}

This study gives an assessment of the extent of social media on COVID-19 vaccination among Aseer populations. There is a high degree of awareness indicated, but there is a possibility for spreading misleading information 
via social media. The likelihood for participants to be vaccinated increased through social media follow-up despite the negative impacts. Social media that can share up-to-date scientific information about vaccination must be utilized perfectly by the government to help people make decisions about accepting vaccines. The public should improve their awareness toward the correct medical information by consulting healthcare professionals or looking after the correct knowledge from reliable sources.

\section{Acknowledgment}

The authors would like to thank King Khalid University, Deanship of Scientific research for funding this research through grant number R.G.P.1/209/41 for small group research project.

\section{Disclosure}

The authors report no conflicts of interest in this work.

\section{References}

1. Tsao SF, Chen H, Tisseverasinghe T, Yang Y, Li L, Butt ZA. What social media told us in the time of COVID-19: a scoping review. Lancet Digit Health. 2021;3(3):e175-e194. doi:10.1016/S25897500(20)30315-0

2. COVID-19 Coronavirus Pandemic. Available from: https://www. worldometers.info/coronavirus/. Accessed August 25, 2021.

3. Galloway SE, Paul P, MacCannell DR, et al. Emergence of SARS-CoV-2 B.1.1.7 Lineage - United States, December 29, 2020-January 12, 2021. MMWR Morb Mortal Wkly Rep. 2021;70 (3):95-99. doi:10.15585/mmwr.mm7003e2

4. Torjesen I. Covid-19: delta variant is now UK's most dominant strain and spreading through schools. BMJ. 2021;373:n1445. doi:10.1136/ bmj.n1445

5. Basch CE, Basch CH, Hillyer GC, Meleo-Erwin ZC, Zagnit EA. YouTube Videos and Informed Decision-Making About COVID-19 Vaccination: successive Sampling Study. JMIR Public Health Surveillance. 2021;7(5):e28352. doi:10.2196/28352

6. Hou Z, Tong Y, Du F, et al. COVID-19 Vaccine Hesitancy, Confidence, and Public Engagement: a Global Social Listening Study. J Med Internet Res. 2021;23(6):e27632. doi:10.2196/27632

7. Kekatos M. Nearly $80 \%$ of Americans think that the speedy approval process of a coronavirus vaccine is driven by politics-NOT by proof that shots work. The Harris Poll. Available from: https://theharrispoll. com/nearly-80-of-americans-think-that-the-speedy-approval-processof-a-coronavirus-vaccine-is-driven-by-politics-not-by-proof-thatshots-work/. Accessed March 1, 2020.

8. McAteer J, Yildirim I, Chahroudi A. The VACCINES Act: deciphering Vaccine Hesitancy in the Time of COVID-19. Clin Infect Dis. 2020;71(15):703-705. doi:10.1093/cid/ciaa433

9. Harrison EA, Wu JW. Vaccine confidence in the time of COVID-19. Eur J Epidemiol. 2020;35(4):325-330. doi:10.1007/s10654-020-00634-3

10. Freberg K, Palenchar MJ, Veil SR. Managing and sharing H1N1 crisis information using social media bookmarking services. Public Relat Rev. 2013;39(3):178-184. doi:10.1016/j.pubrev.2013.02.007

11. Giustini D, Ali SM, Fraser M, Kamel Boulos MN. Effective uses of social media in public health and medicine: a systematic review of systematic reviews. Online J Public Health Inform. 2018;10(2):e215. doi:10.5210/ojphi.v10i2.8270
12. Al-Dmour H, Masa'deh R, Salman A, Abuhashesh M, Al-Dmour R. Influence of Social Media Platforms on Public Health Protection Against the COVID-19 Pandemic via the Mediating Effects of Public Health Awareness and Behavioral Changes: integrated Model. J Med Internet Res. 2020;22(8):e19996. doi:10.2196/19996

13. Bridgman A, Merkley E, Loewen PJ, et al. The causes and consequences of COVID-19 misperceptions: understanding the role of news and social media. Harvard Kennedy School Misinformation Rev. 2020;1(3). doi:10.37016/mr-2020-38

14. Tang L, Bie B, Park SE, Zhi D. Social media and outbreaks of emerging infectious diseases: a systematic review of literature. $\mathrm{Am}$ J Infect Control. 2018;46(9):962-972. doi:10.1016/j.ajic.2018.02.010

15. Reynolds BSM. Crisis and emergency risk communication as an integrative model. $J$ Health Commun. 2005;10(1):43-55. doi:10.1080/10810730590904571

16. Meadows CW, Meadows CZ, Tang L, Liu W. Unraveling public health crises across stages: understanding Twitter emotions and message types during the California measles outbreak. Commun Stud. 2019;70(4):453-469. doi:10.1080/10510974.2019.1582546

17. Hu B, Zhang D. Channel selection and knowledge acquisition during the 2009 Beijing H1N1 flu crisis: a media system dependency theory perspective. Chin J Commun. 2014;7(3):299-318. doi:10.1080/ 17544750.2014.926951

18. Infodemic management. World Health Organization; 2021. Available from: https://www.who.int/teams/risk-communication/infodemicmanagement. Accessed December 11, 2021.

19. Almaghaslah D, Alsayari A, Kandasamy G, Vasudevan R. COVID19 Vaccine Hesitancy among Young Adults in Saudi Arabia: a Cross-Sectional Web-Based Study. Vaccines. 2021;9(4). doi:10.3390/vaccines 9040330

20. Benis A, Khodos A, Ran S, Levner E, Ashkenazi S. Social Media Engagement and Influenza Vaccination During the COVID-19 Pandemic: cross-sectional Survey Study. J Med Internet Res. 2021;23(3):e25977. doi:10.2196/25977

21. Benis A, Seidmann A, Ashkenazi S. Reasons for Taking the COVID-19 Vaccine by US Social Media Users. Vaccines. 2021;9 (4):315. doi:10.3390/vaccines9040315

22. Lee JJ, Kang KA, Wang MP, et al. Associations Between COVID-19 Misinformation Exposure and Belief With COVID-19 Knowledge and Preventive Behaviors: cross-Sectional Online Study. J Med Internet Res. 2020;22(11):e22205. doi:10.2196/22205

23. Eibensteiner F, Ritschl V, Nawaz FA, et al. People's Willingness to Vaccinate Against COVID-19 Despite Their Safety Concerns: twitter Poll Analysis. J Med Internet Res. 2021;23(4):e28973. doi:10.2196/ 28973

24. Greenwood B. The contribution of vaccination to global health: past, present and future. Philosophical transactions of the Royal Society of London. Series B Biol Sci. 2014;369(1645):20130433. doi:10.1098/ rstb.2013.0433

25. Bloom DE, Cadarette D, Ferranna M, Hyer RN, Tortorice DL. How New Models Of Vaccine Development For COVID-19 Have Helped Address An Epic Public Health Crisis. Health Affairs. 2021;40 (3):410-418. doi:10.1377/hlthaff.2020.02012

26. Lurie N, Saville M, Hatchett R, Halton J. Developing Covid-19 Vaccines at Pandemic Speed. $N$ Engl $J$ Med. 2020;382 (21):1969-1973. doi:10.1056/NEJMp2005630

27. Mukherjee SBD, Hamburg M, Weiss S, Yancopoulos G. Can a Vaccine for Covid-19 Be Developed in Record Time? New York Times Magazine. 2020;2:48.

28. Chou WS, Budenz A. Considering Emotion in COVID-19 Vaccine Communication: addressing Vaccine Hesitancy and Fostering Vaccine Confidence. Health Commun. 2020;35(14):1718-1722. doi:10.1080/10410236.2020.1838096

29. Gao Q, Bao L, Mao H, Wang L, Xu K, Yang M. Development of an inactivated vaccine candidate for SARS-CoV-2. Science. 2020;369 (6499):77-81. doi:10.1126/science.abc1932 
30. Haque A, Pant AB. Efforts at COVID-19 Vaccine Development: challenges and Successes. Vaccines. 2020;8:4.

31. Pérez-Escoda A, Jiménez-Narros C, Perlado-lamo-de-espinosa $M$, Pedrero-Esteban LM. Social Networks' Engagement During the COVID-19 Pandemic in Spain: health Media vs. Healthcare Professionals. Int $J$ Environ Res Public Health. 2020;17:14. doi:10.3390/ijerph17145261

32. Jordan SE, Hovet SE, Fung ICH, Liang H, Fu KW, Tse ZTH. Using Twitter for public health surveillance from monitoring and prediction to public response. Data. 2019;4(1):6. doi:10.3390/data4010006

33. Shah Z, Surian D, Dyda A, Coiera E, Mandl KD, Dunn AG. Automatically Appraising the Credibility of Vaccine-Related Web Pages Shared on Social Media: a Twitter Surveillance Study. J Med Internet Res. 2019;21(11):e14007. doi:10.2196/14007

34. Sinnenberg L, Buttenheim AM, Padrez K, Mancheno C, Ungar L, Merchant RM. Twitter as a Tool for Health Research: a Systematic Review. Am J Public Health. 2017;107(1):e1-e8. doi:10.2105/ AJPH.2016.303512

35. Steffens MS, Dunn AG, Wiley KE, Leask J. How organisations promoting vaccination respond to misinformation on social media: a qualitative investigation. BMC Public Health. 2019;19(1):1348. doi:10.1186/s12889-019-7659-3

36. Kim L, Fast SM, Markuzon N. Incorporating media data into a model of infectious disease transmission. PLoS One. 2019;14(2):e0197646. doi:10.1371/journal.pone. 0197646

37. Radzikowski J, Stefanidis A, Jacobsen KH, Croitoru A, Crooks A, Delamater PL. The Measles Vaccination Narrative in Twitter: a Quantitative Analysis. JMIR Public Health Surveillance. 2016;2 (1):e1-e1. doi:10.2196/publichealth.5059

38. Fung ICH, Fu KW, Chan CH, et al. Social Media's Initial Reaction to Information and Misinformation on Ebola, August 2014: facts and Rumors. Public Health Rep. 2016;131(3):461-473. doi:10.1177/ 003335491613100312

39. Sharma M, Yadav K, Yadav N, Ferdinand KC. Zika virus pandemic-analysis of Facebook as a social media health information platform. Am J Infect Control. 2017;45(3):301-302. doi:10.1016/j. ajic.2016.08.022
40. Jimenez D. Covid-19 vaccines: the role of social media in disinformation. Pharmaceutical Technol. 2021;4:5487.

41. Al-Hanawi MK, Angawi K, Alshareef N, et al. Knowledge, Attitude and Practice Toward COVID-19 Among the Public in the Kingdom of Saudi Arabia: a Cross-Sectional Study. Front Public Health. 2020;8:217. doi:10.3389/fpubh.2020.00217

42. Alnasser AHA, Al-Tawfiq JA, Al Kalif MSH, et al. The positive impact of social media on the level of COVID-19 awareness in Saudi Arabia: a web-based cross-sectional survey. Le infezioni in medicina. 2020;28(4):545-550.

43. Smith N Social media vital for COVID vaccine success. Available from: https://www.uwa.edu.au/news/article/2021/march/social-media -vital-for-covid-vaccine-success. Accessed November 25, 2021.

44. Hsiang S, Allen D, Annan-Phan S, et al. The effect of large-scale anti-contagion policies on the COVID-19 pandemic. Nature. 2020;584(7820):262-267. doi:10.1038/s41586-020-2404-8

45. Bhattacharya C, Chowdhury D, Ahmed N, et al. The nature, cause and consequence of COVID-19 panic among social media users in India. Soc Netw Anal Min. 2021;11(1):53. doi:10.1007/s13278-021-00750-2

46. Garrett L. COVID-19: the medium is the message. Lancet. 2020;395 (10228):942-943. doi:10.1016/S0140-6736(20)30600-0

47. Ball P, Maxmen A. The epic battle against coronavirus misinformation and conspiracy theories. Nature. 2020;581(7809):371-374. doi:10.1038/d41586-020-01452-z

48. Rosenberg H, Syed S, Rezaie S. The Twitter pandemic: the critical role of Twitter in the dissemination of medical information and misinformation during the COVID-19 pandemic. Cjem. 2020;22 (4):418-421. doi:10.1017/cem.2020.361

KadamAB, AtreSR. Negative impact of social media panic during the COVID-19 outbreak in India. $J$ Travel Med. 2020;27(3):254. doi: $10.1093 / \mathrm{jtm} / \mathrm{taaa} 057$
Patient Preference and Adherence

\section{Publish your work in this journal}

Patient Preference and Adherence is an international, peer-reviewed, open access journal that focusing on the growing importance of patient preference and adherence throughout the therapeutic continuum. Patient satisfaction, acceptability, quality of life, compliance, persistence and their role in developing new therapeutic modalities and compounds to optimize clinical outcomes for existing disease states are major areas of interest for the journal. This journal has been accepted for indexing on PubMed Central. The manuscript management system is completely online and includes a very quick and fair peer-review system, which is all easy to use. Visit http:// www.dovepress.com/testimonials.php to read real quotes from published authors. 